\title{
HYPOTENSIVE ACTIVITY OF THYMOQUINONE IN NORMOTENSIVE RATS AND ITS RECEPTOR MECHANISMS
}

\author{
MARWAN SAAD AZZUBAIDI ${ }^{*}$, HUSSAM MIZHER ${ }^{2}$, AHMED GHAZI ALATTRAQCHI ${ }^{3}$ \\ 1Pharmacology Unit, Faculty of Medicine, Universiti Sultan Zainal Abidin Malaysia, ${ }^{2}$ Faculty of Pharmacy, International Islamic University \\ Malaysia, ${ }^{3}$ Biochemistry Unit, Faculty of Medicine, Universiti Sultan Zainal Abidin Malaysia \\ Email: mazzubaidi@gmail.com \\ Received: 04 Jan 2017 Revised and Accepted: 19 Jun 2017
}

\section{ABSTRACT}

Objective: The objectives of the current study were to confirm the blood pressure lowering effect of thymoquinone (TQ) and to investigate its mechanism through muscarinic and $\beta$-adrenergic receptors.

Methods: Mean arterial blood pressure (MAP) was recorded using the non-invasive blood pressure tail-cuff technique. A dose-response relationship was obtained after using $3 \mathrm{TQ}$ doses $(2.5,5$ and $10 \mathrm{mg} / \mathrm{kg})$ intraperitoneally to 3 different groups $(n=5)$ of adult rats under pentobarbital anesthesia. MAP was then measured for another 2 animal groups pretreated either with atropine (P-at) or propranolol (P-pro) followed by $10 \mathrm{mg} / \mathrm{kg} \mathrm{TQ}$.

Results: TQ produced a significant dose-dependent blood pressure and heart rate lowering effect. TQ-induced MAP reduction was significantly less pronounced in $\mathrm{P}$-at $(12 \pm 2.8 \mathrm{mmHg})$ than non-pretreated group $(29 \pm 3.2 \mathrm{mmHg})$ with $\mathrm{P}<0.01$. Conversely, TQ-induced MAP reduction in P-pro $(28 \pm 3.4 \mathrm{mmHg})$ did not demonstrate a significant difference from the non-pretreated group $(29 \pm 3.2 \mathrm{mmHg})$ with $\mathrm{P}>0.05$.

Conclusion: This study confirms the dose-related hypotensive effect of TQ and provides an evidence for the traditional use of Nigella sativa for the treatment of hypertension. The mechanism of TQ-induced hypotension involves at least in part activation of vascular muscarinic receptors, but not $\beta$-adrenergic receptors.

Keywords: Thymoquinone, Atropine, Propranolol, Mean arterial pressure, Tail cuff, Cholinergic receptors, Adrenergic receptors, Heart rate

(c) 2017 The Authors. Published by Innovare Academic Sciences Pvt Ltd. This is an open access article under the CC BY license (http://creativecommons.org/licenses/by/4.0/) DOI: http://dx.doi.org/10.22159/ijpps.2017v9i8.16923

$\mathrm{TQ}$ is considered the main active constituent in Nigella sativa volatile oil, and one of the natural products that show a potential in reducing blood pressure [1]. This research aims to evaluate the hypotensive activity of $\mathrm{TQ}$ and mechanism of action. Several studies confirmed that hypertension was not controlled by a single therapy and require at least two medications from two different groups [2,3].

Male Sprague-Dawley rats weighing (210-270 g) were used in the experiment and were kept in the animal laboratory, faculty of pharmacy, IIUM. This protocol was approved by the integrated center for research animal care and use (ICARCU), IIUM $\backslash 519 \backslash 14 \backslash 3 \backslash$ ICARCU on $26^{\text {th }}$ of February 2014. Rats were allowed free access to normal diet and tap water. A $12 \mathrm{~h}$ day $\backslash$ light cycle was set with lights turned on at 8:00am; temperature was kept at $26 \pm 1^{\circ} \mathrm{C}$.

Blood pressure and heart rate were measured non-invasively using the tail-cuff technique by CODA non-invasive blood pressure system (Kent scientific corporation, USA). Mean arterial blood pressure (MAP) was obtained after recording systolic and diastolic blood pressure readings. Throughout the period of the experiment, animals' temperature was kept stable using warming platform, the temperature measured every 15 min with IR thermometer and maintained at $28 \pm 1^{\circ} \mathrm{C}$.
Rats were moved to the laboratory $30 \mathrm{~min}$ before starting the experiment and anesthetized with $60 \mathrm{mg} / \mathrm{kg}$ sodium pentobarbital intraperitoneally using Camilla's method [4] and allowed for at least $45 \mathrm{~min}$ to achieve anesthesia and stable blood pressure readings before conducting the experiment.

TQ (Sigma-Aldrich, USA) in three different doses $(2.5,5$ and $10 \mathrm{mg} / \mathrm{kg})$ was dissolved in dimethylsulfoxide DMSO. Each dose was tested in a different group of animals $(n=5)$, the effect of each dose was recorded immediately after administration and at 1 min time interval for the following $60 \mathrm{~min}$. The maximum effect was observed around (27-34) min after injection. The average of the lowest four consecutive acceptable cycles was considered as the maximum response and compared with the baseline obtained prior TQ administration to achieve the net reduction for each dose.

The tested doses showed a dose-dependent lowering effect on both MAP and HR, where $2.5 \mathrm{mg} / \mathrm{kg}$ decreased MAP by $8 \mathrm{mmHg}$ and heart rate by $14 \mathrm{bpm}$, while 5 and $10 \mathrm{mg} / \mathrm{kg}$ lowered MAP by 12 and 29 $\mathrm{mmHg}$ and HR by 21 and $44 \mathrm{bpm}$, respectively. The magnitudes of MAP reduction achieved by all the studied doses were statistically significant with a $(P<0.01)$ compared to average readings of baseline before administering TQ. Table 1 and 2 summarize the three TQ doses effect on MAP and HR.

Table 1: TQ dose-dependent effect on MAP

\begin{tabular}{|c|c|c|c|c|c|c|}
\hline \multirow[t]{3}{*}{ Measured parameter } & \multicolumn{6}{|c|}{ TQ dose (mg/kg) } \\
\hline & \multicolumn{2}{|c|}{2.5} & \multicolumn{2}{|l|}{5} & \multicolumn{2}{|l|}{10} \\
\hline & Before TQ & After TQ & Before TQ & After TQ & Before TQ & After TQ \\
\hline Mean MAP (mmHg) & $101.4 \pm 3$ & $93.7 \pm 2.2$ & $102.6 \pm 4.5$ & $90.3 \pm 3$ & $110.2 \pm 3.1$ & $81.1 \pm 2$ \\
\hline Net reduction $(\mathrm{mmHg})$ & $* 7.6 \pm 1$ & & $* 12.3 \pm 3.7$ & & $* 29.2 \pm 3.2$ & \\
\hline
\end{tabular}

*A statistically significant difference $(P<0.01)$ for the net reduction in MAP after TQ10 treatment compared to the baseline reached before TQ administration by paired student $t$-test. $\mathrm{n}=5$, data given in mean $\pm \mathrm{SD}$. $\mathrm{TQ}=$ thymoquinone, $\mathrm{MAP}=$ mean arterial pressure. 
Table 2: TQ dose-dependent effect on HR

\begin{tabular}{|c|c|c|c|c|c|c|}
\hline \multirow[t]{3}{*}{ Measured parameter } & \multicolumn{6}{|c|}{ TQ dose (mg/kg) } \\
\hline & \multicolumn{2}{|l|}{2.5} & \multicolumn{2}{|l|}{5} & \multicolumn{2}{|l|}{10} \\
\hline & Before TQ & After TQ & Before TQ & After TQ & Before TQ & After TQ \\
\hline Mean HR (bpm) & $377.1 \pm 5$ & $363 \pm 3.3$ & $383.8 \pm 8$ & $362.7 \pm 5.7$ & $362.9 \pm 7$ & $319.2 \pm 3.3$ \\
\hline Net reduction (bpm) & $* 14.2 \pm 3.8$ & & $* 21.1 \pm 6.8$ & & $* 43.7 \pm 5.3$ & \\
\hline
\end{tabular}

* A statistically significant difference with a $P<0.01$ for the net reduction in HR after TQ10 treatment compared to the baseline reached before TQ administration by paired student $t$-test. $\mathrm{n}=5$, data given in mean $\pm \mathrm{SD}$. $\mathrm{TQ}=$ thymoquinone, $\mathrm{MAP}=$ mean arterial pressure.

Atropine sulphate (Merck, Germany) and propranolol (Calbiochem, Japan) were prepared by dissolving each in normal saline. Additional two groups of animals $(\mathrm{n}=5)$ received either atropine $1 \mathrm{mg} / \mathrm{kg}$ [5] or propranolol $0.6 \mathrm{mg} / \mathrm{kg}$ [6] after anesthesia. Then rats were left for around $45 \mathrm{~min}$ before TQ $10 \mathrm{mg} / \mathrm{kg}$ was injected intraperitoneally. MAP and HR were recorded for the following $90 \mathrm{~min}$. The lowest readings were considered as the maximum lowering activity of TQ at the respective dose.

Data were expressed as mean $\pm(\mathrm{SD})$ and analyzed by student $t$-test, paired for the comparison within the group and unpaired to compare among different groups, where a $(P$ value $<0.05)$ was considered statistically significant.

Pretreatment of atropine significantly inhibited the decrease in both MAP and HR caused by TQ10. TQ10 alone decreased MAP by $29 \pm 3.2$ $\mathrm{mmHg}$ and $\mathrm{HR}$ by $44 \pm 5.3 \mathrm{bpm}$. Conversely, TQ10 in atropine pretreated group lowered MAP only by $12 \pm 2.8 \mathrm{mmHg}$ and HR by $13 \pm 2.5 \mathrm{bpm}$.

The differences in MAP and HR values with and without atropine pretreatment were statistically significant with a $(P<0.01)$ as shown in (fig. 1).
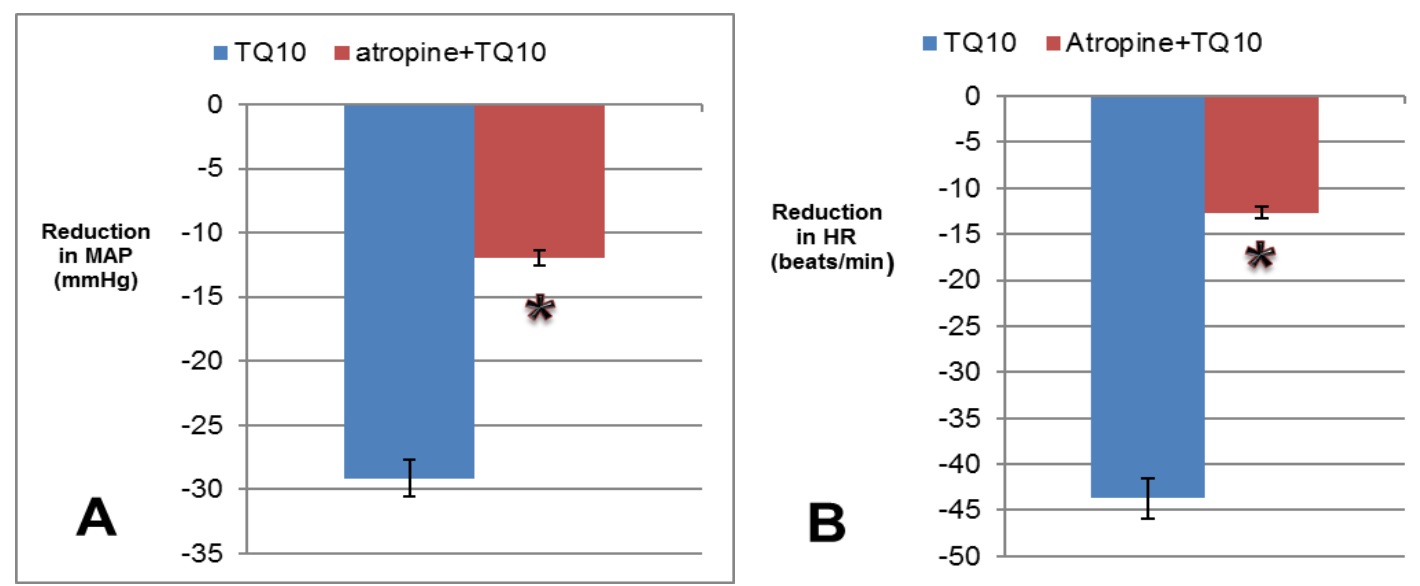

Fig. 1: The effect of TQ10 on (A) MAP and (B) HR with and without pretreatment with atropine. ${ }^{*} P<0.01$ for the net reduction after TQ10 pre-treated as compared to the other group by unpaired student $t$-test. $n=5$, data given in mean $\pm \mathrm{SD}$. $\mathrm{TQ}=$ thymoquinone, $\mathrm{MAP}=$ mean arterial pressure

TQ10 lowered the MAP by $29 \pm 3.2 \mathrm{mmHg}$ and lowered the HR by $44 \pm 5.3 \mathrm{bpm}$ in the non-pretreated rat group. Similarly, in the propranolol pre-treatment group, TQ10 decreased the MAP and HR by $28 \pm 3.4 \mathrm{mmHg}$ and $39 \pm 3.6 \mathrm{bpm}$, respectively as shown in (fig. 2).
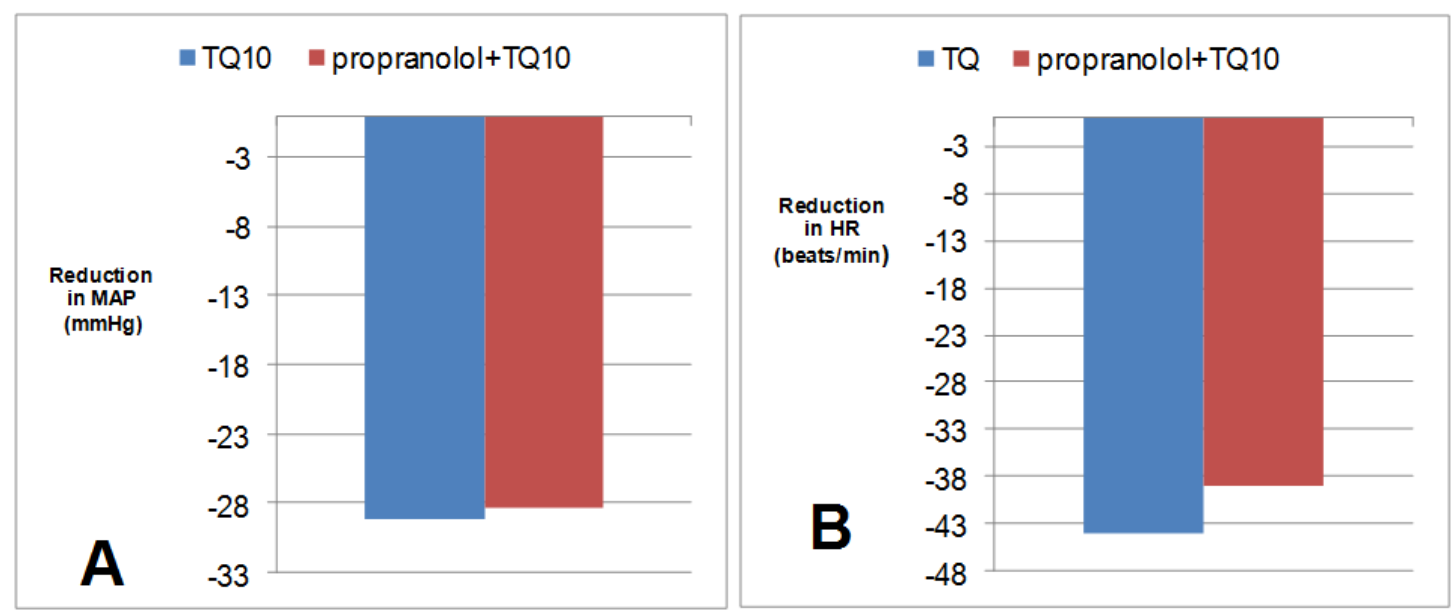

Fig. 2: The effect of propranolol pre-treatment on (A) MAP and (B) HR reduction by TQ10. No statistically significant difference (P>0.05) for the net reduction in MAP and HR after TQ10 introduction to animals pre-treated with propranolol by unpaired student $t$-test. $n=5$, data given in mean $\pm \mathrm{SD}$. $\mathrm{TQ}=$ thymoquinone, $\mathrm{MAP}=$ mean arterial pressure 
Based on a previous study exploring the LD50 of TQ $(57.5 \mathrm{mg} \backslash \mathrm{kg}$ after intraperitoneal administration) [7], the TQ doses were chosen since the pharmacological relevant dose equals one tenth of the $\mathrm{LD}_{\mathbf{5 0}}$.

The volatile oil of Nigella sativa and TQ, the major active constituent were found to possess cardio depressant effect by decreasing the arterial blood pressure and the heart rate [8]. Those findings were in agreement with the results of the present study, where TQ reduced both MAP and heart rate in a dose-dependent manner.

The extent of the reduction in both parameters was slightly more pronounced in the current research compared to El-Taher's findings. This might be attributed to the differences in the doses as well as the route of administration between the studies. While El-Taher and coworkers used relatively smaller doses by intravenous injection, higher doses were used in our study via the intraperitoneal route. These outcomes may also lead us to expect that TQ undergoes the firstpass metabolism after intraperitoneal or oral administration as the previous work was done using smaller doses $(0.2-1.6 \mathrm{mg} / \mathrm{kg}$ iv) compared to ours 5 and $10 \mathrm{mg} / \mathrm{kg}$ i. p. Despite the large dose difference between the studies, only trivial differences in MAP reduction were found in the results comparatively.

The substantial capacity of TQ to decrease MAP and heart rate in the non-atropinized group versus the atropinized led us to conclude that $\mathrm{TQ}$ acts via activation the muscarinic receptors $\left(\mathrm{M}_{2}\right)$ on heart lowering the heart rate and $\left(\mathrm{M}_{3}\right)$ on the blood vessels causing vasodilation as a part of its mechanism.

These results are in line with previous study findings that the stimulation of cholinergic muscarinic receptors was responsible for the TQ cardio depressant activity [8].

The absence of significant statistical difference between the propranolol pre-treated group and the TQ only treated group suggests that neither the cardiac $\beta 1$ nor the vascular $\beta 2$ adrenergic receptors have any role in TQ mechanism to reduce blood pressure and heart rate. This fact led us to exclude the cardiac and vascular $\beta$ adrenergic receptors as potential binders to $\mathrm{TQ}$.

Interestingly, other researchers found that propranolol pre-treatment did not influence the bronchodilator effect of TQ in isolated guinea-pig trachea suggesting that the latter has no role mediated via $\beta 2$ adrenergic receptors in trachea [9]. In this research, TQ showed a dose-dependent blood pressure lowering effect in normotensive rats, an effect that can be inhibited by pretreatment of atropine while propranolol did not inhibit TQ effect which suggests a role of muscarinic receptors activation by TQ. However, $\beta$ adrenergic receptors appeared to be unaffected by TQ administration. This result rules out the involvement of $\beta$ adrenergic receptors in the hypotensive activity of TQ.

\section{AUTHOR CONTRIBUTION}

Dr. Marwan Azzubaidi was the main author and the designer of the whole study. Hussam Mizher was the co-researcher conducting the experiment on the experimental animals. Ahmed Ghazi Al-Attraqchi prepared all chemical substances and carried out the statistical analyses.

\section{ACKNOWLEDGMENT}

This work was supported by Research Management Centre, International Islamic University Malaysia with Grants number (EDW B 14-214-1099).

\section{CONFLICT OF INTERESTS}

The authors declare that there is no conflict of interests

\section{REFERENCES}

1. El-Tahir KEH. The black seed Nigella sativa linnaeus-a mine for multi cures: a plea for urgent clinical evaluation of its volatile oil. J Taibah University Med Sci 2006;1:1-19.

2. Black HR, Elliott WJ, Grandits G, Grambsch P, Lucente T, White WB, et al. Principal results of the Controlled onset verapamil investigation of the cardiovascular end points (convince) trial. JAMA 2003;289:2073-82.

3. Dahlöf B, Devereux RB, Kjeldsen SE, Julius S, Beevers G, De Faire $\mathrm{U}$, et al. Cardiovascular morbidity and mortality in the losartan intervention for endpoint reduction in hypertension study (LIFE): a randomised trial against atenolol. Lancet 2002; 359:995-1003.

4. Rasmussen C. An alternative method for rat fixation when giving subcutaneous, intramuscular and intraperitoneal injections. Scand J Lab Anim Sci 1999;26:156-9.

5. Praman S, Mulvany MJ, Williams DE, Andersen RJ, Jansakul C. Hypotensive and cardio-chronotropic constituents of Tinospora crispa and mechanisms of action on the cardiovascular system in anesthetized rats. J Ethnopharmacol 2012;140:166-78.

6. Praman S, Mulvany MJ, Allenbach Y, Marston A, Hostettmann K, et al. Effects of an<i>n</i>-butanol extract from the stem of Tinospora crispa on blood pressure and heart rate in anesthetized rats. J Ethnopharmacol 2011;133:675-86.

7. Al-Ali A, Alkhawajah AA, Randhawa MA, Shaikh NA. Oral and intraperitoneal LD50 of thymoquinone, an active principle of Nigella sativa, in mice and rats. J Ayub Med Coll Abbottabad 2008;20:25-7.

8. El Tahir KEH. The cardiovascular actions of the volatile oil of the black seed (Nigella sativa) in rats: elucidation of the mechanism of action. Gen Pharmacol 1993;24:1123-31.

9. Al-Majed AA, Daba MH, Asiri YA, Al-Shabanah OA, Mostafa AA, ElKashef HA. Thymoquinone-induced relaxation of the guinea-pig isolated trachea. Res Commun Mol Pathol Pharmacol 2000; 110:333-45.

\section{How to cite this article}

- Marwan Saad Azzubaidi, Hussam Mizher, Ahmed Ghazi Alattraqchi. Hypotensive activity of thymoquinone in normotensive rats and its receptor mechanisms. Int J Pharm Pharm Sci 2017;9(8):216-218. 